\author{
Danuta Bryja \\ Dr hab. inż., prof. PWr \\ Wydział Budownictwa Lądowego \\ i Wodnego, Politechnika \\ Wrocławska \\ danuta.bryja@pwr.edu.pl

\section{Wojciech Chojnacki} \\ Mgr inż. \\ (student) Wydział Architektury, \\ Politechnika Wrocławska \\ 211490@student.pwr.edu.pl
}

DOI: 10.35117/A_ENG_19_11_01

\title{
Two-way Hertzian spring in numerical analysis of coupled train-track system vibrations
}

\begin{abstract}
The paper presents and compares two methods for simulation the train-track system vibrations, differing in the wheel-rail contact model used. In the first method, two-way Hertzian spring is used, in the second - a non-deformable constraint. In both methods, a flat computational model is assumed, consisting of an Euler-Bernoulli beam resting on a Winklertype elastic foundation with damping and a set of rail vehicles modeled by dynamic systems with ten degrees of freedom. The results of numerical analysis are presented, in order to determine an influence of the contact constraints' deformability on the vibration simulations. It is found that the replacement of non-deformable contact constraints by two-way Hertzian springs has no significant effect on track vibration simulations and has a little effect on vibration simulations of vehicle body and bogie. The developed simulation method can be used for numerical studies of the phenomenon of instantaneous detachments of wheels from rails, after minor modifications directed to introduce one-way Hertzian springs (i.e. not carrying tensile forces) being a more accurate contact model.
\end{abstract}

Keywords: Train-track system; Vibration simulations; Contact problem; Hertzian spring

\section{Introduction}

The selection of the contact model describing the contact of the wheel of a railway vehicle with a rail is one of the basic problems of computational dynamics of the coupled train-track system. There are many theories in the literature describing phenomena occurring in the wheel-rail contact zone. Their simple classification, developed based on Kalker's known work [1], is presented in monograph [2] from 1984. It is based on the division of the rolling contact theory into several subcategories. The first is a division into exact and simplified theories, where exact theories are based on the assumption that the wheel and rail near the contact surface are treated as elastic half-space, and the constitutive relationships result from the theory of elasticity. In simplified theories, parameters that depend only on the contact surface of two bodies are used, without introducing the concept of half-space. In the next division, dynamic theories are distinguished in which inertial effects are considered, and quasi-static theories in which these effects are ignored. The most obvious division is the distinction between three-dimensional and two-dimensional theories. In the monograph Bosso et al. [3] from 2013, you can find a comprehensive overview of contemporary contact models, 
generally very complex and using FEM modeling. The models presented here are used in the issues of rail vehicle mechanics.

Much simpler contact models are used in numerical simulations of vibrations of the coupled train-track system, designed for rail track dynamics analysis. Usually, the contact model is the so-called Hertzian spring contact [4], [5], which is most often treated as a bilateral stress, i.e. carrying both compression and extension. At high travel speeds, the twoway contact model deviates significantly from reality because it ignores the momentary detachment of wheelsets from the rails. One-way spring, transferring only compression, among others in the work of Podwórna and Klasztorny [6] devoted to the research on the impact of selected features of railway vehicles on the vibrations of a freely supported beam idealizing a beam bridge. Sets of railway vehicles in this work were modeled in turn as: systems of moving forces, unsprung masses and one- and two-mass viscoelastic oscillators. Despite extensive and interesting analyzes, no comparison with alternative solutions using two-way spring has been presented.

The work [6] inspired the authors of this article to undertake research whose final goal is to assess the impact of using one-way Hertzian spring in simulations of train-track vibrations by comparing with the results obtained using a typical two-way spring. This article presents the first stage of research in which a method of vibration simulation of the system was developed, taking into account the typical two-way Hertzian spring at the contact between wheelsets and rails. The method is designed so that, after minor modifications planned in the second stage of work, it allows calculations to be made using a one-way contact spring. The numerical part compares the results of simulations of displacement courses, as well as velocity and acceleration of vibrations of individual elements of a selected railway vehicle and selected track points, determined using two algorithms - taking into account two-way Hertzian spring and ignoring this spring, i.e. assuming a non-deformable stress movable wheel-rail contact. The effect of deformation of the contact stress on the results of train-track vibration simulation was also investigated.

\section{Simulation method of train-track system vibrations}

The subject of the considerations are vertical vibrations of a flat model of the system consisting of two coupled dynamic subsystems: 1) a set of four-axle railway vehicles, each of which is treated as a discrete system with 10 degrees of freedom, and 2) a track being a continuous Euler-Bernoulli beam resting on an elastically ground - Winkler type suppressor. The overall layout of the system is shown in Figure 1. It was assumed that the set of vehicles (train) travels at a constant speed $v$ along a section of the deformable track with a length $L$, large enough for the section to model an infinitely long track in the numerical sense. Before entering section $L$ and after leaving the section, the train moves on a non-compliant track. Each vehicle is a system of three mass discs replacing the body and carriages, and four concentrated masses modeling wheelsets. These elements are connected by linear-elastic ties and viscous dampers that model the two-stage suspension. Between the wheelsets and the track, two-way linear-elastic Hertzian spring with stiffness $k_{\mathrm{H}}$ was introduced. The dynamic model of the vehicle is shown in Figure 2, along with the designations of dynamic mass element displacements. 


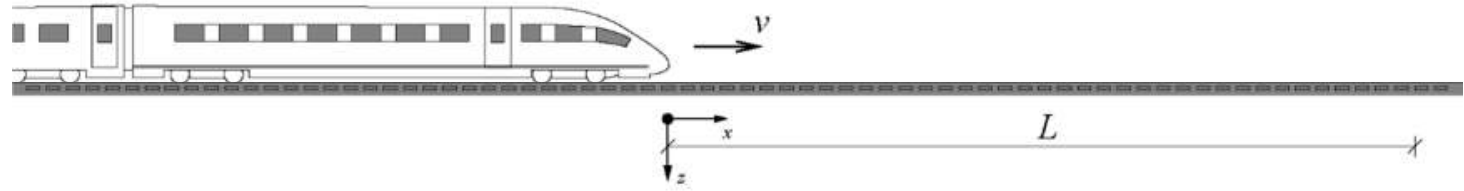

1. The diagram of the train-track system

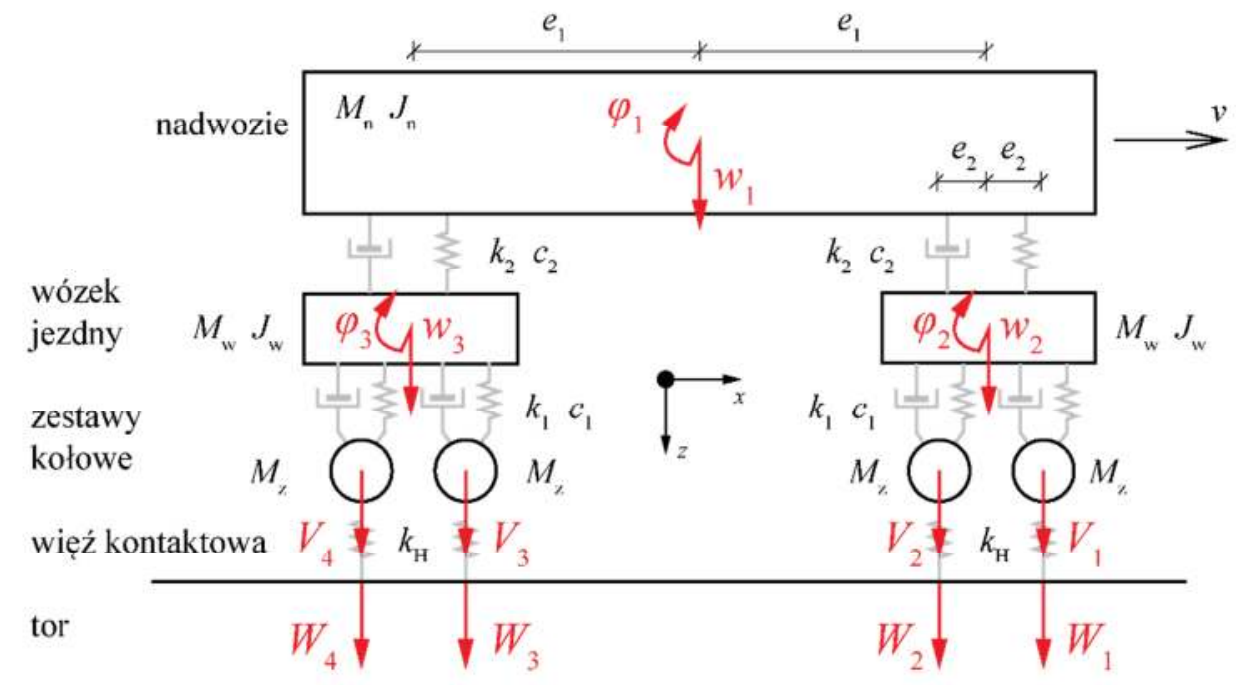

2. Dynamic vehicle model

A rigid coupling was installed between the vehicles in the longitudinal direction. At the initial moment $t=0$, the front of the train is at the left extreme point of the flexible section of the track, with the coordinate $\mathrm{x}=0$. Vehicles entering the tested section of the track are in a state of static equilibrium, which means that all deformable springs of the vehicle have been deformed due to their weight structural elements of the train, transferred by the contact spring to the non-sensitive track.

A rigid coupling was installed between the vehicles in the longitudinal direction. At the initial moment $t=0$, the front of the train is at the left extreme point of the flexible section of the track, with the coordinate $x=0$. Vehicles entering the tested section of the track are in a state of static equilibrium, which means that all deformable springs of the vehicle have been deformed due to their weight structural elements of the train, transferred by the contact spring to the non-sensitive track. The dynamic displacements of the vehicle marked in the figure are measured from a statically balanced reference configuration. The railway track was defined as a Euler-Bernoulli beam resting on a deformable Winkler type elastic foundation with damping. Substrate parameters, i.e. the coefficient of elasticity $k$ and damping $c$ are constant. The beam is prismatic, inertial, perfectly rectilinear, it replaces both railways. The beam material is linear-elastic. The damping resulting from rheological properties of the rail material was taken into account, according to the Voigt-Kelvin model. 


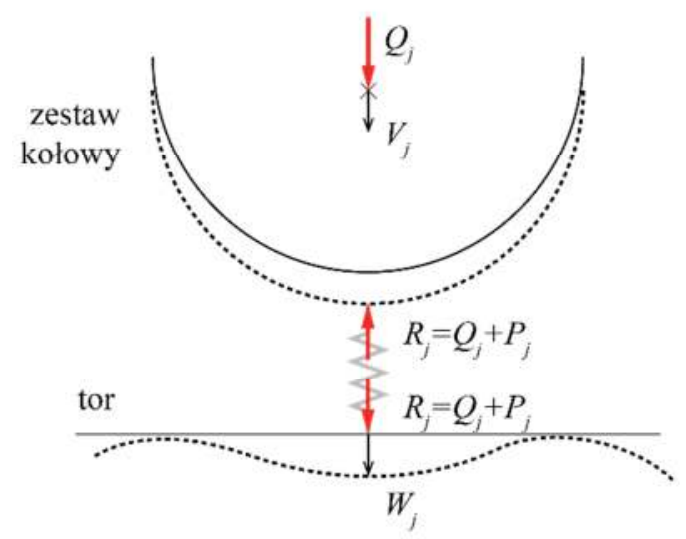

3. Balance of forces at the contact of the wheelset with the track

Figure 3 presents forces acting at the junction of the $\mathrm{j}$-wheelset with the rail and dynamic displacements of subsystems at the point of contact: dynamic displacement of the wheelset $V_{j}$ $(t)$ and track displacement $W_{j}(t)$. The figure shows that the track is loaded by the contact stress reaction $R_{j}(t)=Q_{j}+P_{j}(t)$, consisting of static axial pressure $Q_{j}$ and the force of dynamic interaction between subsystems $P_{j}(t)$. The wheelset, in addition to the reaction of the $R_{j}(t)$ constraints, is affected by a static force $Q_{j}$, i.e. the weight of the vehicle per axle. It follows that in the equation of vehicle motion

$$
\mathbf{B}_{\mathrm{v}} \ddot{\mathbf{v}}_{i_{\mathrm{v}}}+\mathbf{C}_{\mathrm{v}} \dot{\mathbf{v}}_{i_{\mathrm{v}}}+\mathbf{K}_{\mathrm{v}} \mathbf{v}_{i_{\mathrm{v}}}=\tilde{\mathbf{F}}_{i_{\mathrm{v}}}
$$

there are no static axial loads. The vehicle is loaded only by the forces of the mutual dynamic interaction of the track and the vehicle, which are dynamic components of the reaction of contact springs.

$$
P_{j}(t)=k_{H}\left[V_{j}(t)-W_{j}(t)\right]
$$

The equation of motion (1) was derived by a methodology typical of discrete systems, i.e. based on the energy balance and Lagrange equations. Details of the exit can be found in the work [7]. Vehicle generalized displacement vector $\mathbf{v}_{i_{\mathrm{v}}}=\operatorname{col}\left(\mathbf{r}_{i_{\mathrm{v}}}, \mathbf{V}_{i_{\mathrm{v}}}\right)$ is divided into two blocks $\mathbf{r}_{i_{\mathrm{v}}}=\left[w_{1}, w_{2}, w_{3}, \varphi_{1}, \varphi_{2}, \varphi_{3}\right]_{i_{\mathrm{v}}}^{\mathrm{T}}$ and $\mathbf{V}_{i_{\mathrm{v}}}=\left[V_{1}, V_{2}, V_{3}, V_{4}\right]_{i_{\mathrm{v}}}^{\mathrm{T}}$ (Figure 2), which facilitates the procedure of aggregation of equations (1) saved for subsequent vehicles $i_{\mathrm{v}}=1,2, \ldots, N_{\mathrm{v}}$. The symbol "col" indicates a column matrix composed of vector blocks a ()$^{\mathrm{T}}$ a transposition operation. Index $i_{\mathrm{v}}$ specifies the vehicle number calculated from the front of the train, therefore the number of train axles is $N=4 N_{\mathrm{v}}$ and $j=1,2, \ldots, N$. Using the aggregation procedure described in [7], one obtains the vibration equation of the $N_{\mathrm{v}}$ set of vehicles, kinematically activated by vertical track vibration

$$
\mathbf{B}_{\mathrm{pp}} \ddot{\mathbf{q}}_{\mathrm{p}}+\mathbf{C}_{\mathrm{pp}} \dot{\mathbf{q}}_{\mathrm{p}}+\mathbf{K}_{\mathrm{pp}} \mathbf{q}_{\mathrm{p}}=\tilde{\mathbf{F}}_{\mathrm{p}}
$$

To facilitate the mathematical notation of the coupling of equation (3) with the track vibration equation, two blocks have been distinguished in the generalized displacement vector $\mathbf{q}_{\mathrm{p}}=$ $\operatorname{col}\left(\mathbf{r}, \mathbf{V}_{\mathbf{o}}\right): \mathbf{r}=\operatorname{col}\left(\mathbf{r}_{1}, \mathbf{r}_{2}, \ldots, \mathbf{r}_{N_{\mathrm{v}}}\right)$ and $\mathbf{V}_{\mathbf{o}}=\operatorname{col}\left(\boldsymbol{V}_{1}, \boldsymbol{V}_{2}, \ldots, \boldsymbol{V}_{N_{v}}\right)$, but it is easy to see that in block $\mathbf{V}_{\mathbf{o}}$ the displacements of all subsequent wheelsets are grouped. After entering the continuous numbering $j=1,2, \ldots, N$ can be written as $\mathbf{V}_{\mathbf{o}}=\left[V_{1}, V_{2}, \ldots, V_{N}\right]^{T}$. The vector of 
the right side of equation (3) is of the form $\tilde{\mathbf{F}}_{\mathrm{p}}(t)=\operatorname{col}\left(\varnothing,\left\{k_{H}\right\} \boldsymbol{W}_{\boldsymbol{o}}\right)$, where the symbol $\emptyset$ means a zero vector of size $6 N_{\mathrm{v}},\left\{k_{H}\right\}=\operatorname{diag}\left(k_{H}, k_{H}, \ldots, k_{H}\right)$ is a diagonal matrix of size $N$, and the vector $\mathbf{W}_{\mathbf{o}}=\left[W_{1}, W_{2}, \ldots, W_{N}\right]^{T}$ accumulates track displacement in points of contact with subsequent wheelsets - the so-called tracking displacements [8]. Equation (3) is coupled through tracking displacements $\boldsymbol{W}_{\boldsymbol{o}}$ to the matrix equation of track motion

$$
\mathbf{B}_{\mathrm{tt}} \ddot{\mathbf{q}}_{\mathrm{t}}+\mathbf{C}_{\mathrm{tt}} \dot{\mathbf{q}}_{\mathrm{t}}+\mathbf{K}_{\mathrm{tt}} \mathbf{q}_{\mathrm{t}}=\tilde{\mathbf{F}}_{\mathrm{t}}
$$

which were derived from the known bending equation of Euler-Bernoulli beam, loaded with a set of moving forces

$$
\begin{gathered}
E I \frac{\partial^{4} w(x, t)}{\partial x^{4}}+m \frac{\partial^{2} w(x, t)}{\partial t^{2}} \\
+c \frac{\partial w(x, t)}{\partial t}+k w(x, t)=\sum_{j=1}^{N} R_{j}(t) \delta\left(x-s_{j}\right)
\end{gathered}
$$

$R_{j}(t)=Q_{j}+P_{j}(t)$ is here the reaction of Hertzian contact spring, and the function $s_{j}(t)=$ $v t-d_{j}$ describes the position of the $\mathrm{j}$-th wheelset at the moment $t$, with $d_{j}$ being the distance of the axle of the j-th wheelset from the train front. To transform equation (5) into the form (4), the finite element method was applied in the Galerkin approach (GFEM). The procedure of this transformation is based on solutions formulated in [9], [10] and is described in detail in [7]. After determining the explicit form of the right side vectors in equations (3) and (4), you can write these equations together in the following block form

$$
\begin{gathered}
{\left[\begin{array}{ccc}
\boldsymbol{B}_{r r} & \boldsymbol{B}_{r o} & \mathbf{0} \\
\boldsymbol{B}_{o r} & \boldsymbol{B}_{o o} & \mathbf{0} \\
\mathbf{0} & \mathbf{0} & \boldsymbol{B}_{t t}
\end{array}\right]\left[\begin{array}{c}
\ddot{\boldsymbol{r}}_{\ddot{\boldsymbol{V}}_{o}} \\
\ddot{\boldsymbol{q}}_{t}
\end{array}\right]+\left[\begin{array}{ccc}
\boldsymbol{C}_{r r} & \boldsymbol{C}_{r o} & \mathbf{0} \\
\boldsymbol{C}_{o r} & \boldsymbol{C}_{o o} & \mathbf{0} \\
\mathbf{0} & \mathbf{0} & \boldsymbol{C}_{t t}
\end{array}\right]\left[\begin{array}{c}
\dot{\boldsymbol{r}} \\
\dot{\boldsymbol{V}}_{o} \\
\dot{\boldsymbol{q}}_{t}
\end{array}\right]} \\
+\left[\begin{array}{ccc}
\boldsymbol{K}_{r r} & \boldsymbol{K}_{r o} & \mathbf{0} \\
\boldsymbol{K}_{o r} & \boldsymbol{K}_{o o} & -\widetilde{\boldsymbol{K}}_{o t} \\
\mathbf{0} & -\widetilde{\boldsymbol{K}}_{t o} & \boldsymbol{K}_{t t}+\widetilde{\boldsymbol{K}}_{t t}
\end{array}\right]\left[\begin{array}{c}
\boldsymbol{r} \\
\boldsymbol{V}_{o} \\
\boldsymbol{q}_{t}
\end{array}\right]=\left[\begin{array}{c}
\mathbf{0} \\
\mathbf{0} \\
\widetilde{\boldsymbol{F}}_{Q}
\end{array}\right]
\end{gathered}
$$

where the overwritten tilde distinguishes time-dependent matrixes and vectors, while the obvious time dependence of the generalized displacement vectors $\mathbf{r}(t)$ and $\boldsymbol{V}_{o}(t)$ and the generalized coordinates $\boldsymbol{q}_{t}(t)$ is not marked in the same way. Formulas defining individual blocks of the coefficient matrix and the right side of equation (6) are given in the paper[7].

The vibration simulation method of the train-track system described above is based on the solution of a coupled second-order ordinary differential equation system (6), which can be written collectively in the following general form

$$
\mathbf{B} \ddot{\mathbf{q}}(t)+\mathbf{C} \dot{\mathbf{q}}(t)+\mathbf{K}(t) \mathbf{q}(t)=\mathbf{F}(t)
$$

To assess the impact of introducing two-way Hertzian spring into the computational model of the system under consideration, an alternative, a comparative computational model was formulated replacing the vulnerable contact spring by a rigid stress. This simplest, rigid wheel-rail contact model, often used in the literature (see [6]), leads to the compatibility of track and wheelset displacements at the contact points. In this case, it should be assumed that $\mathrm{V} \boldsymbol{V}_{o}=\boldsymbol{W}_{o}$, and then the train-track equation of motion has a different general form 


$$
\mathbf{B}(t) \ddot{\mathbf{q}}(t)+\mathbf{C}(t) \dot{\mathbf{q}}(t)+\mathbf{K}(t) \mathbf{q}(t)=\mathbf{F}(t)
$$

and block form

$$
\begin{gathered}
{\left[\begin{array}{cc}
\boldsymbol{B}_{r r} & \widetilde{\boldsymbol{B}}_{r t} \\
\widetilde{\boldsymbol{B}}_{t r} & \boldsymbol{B}_{t t}+\widetilde{\boldsymbol{B}}_{t t}
\end{array}\right]\left[\begin{array}{c}
\ddot{\ddot{\boldsymbol{r}}} \\
\ddot{\boldsymbol{q}}_{t}
\end{array}\right]+\left[\begin{array}{ll}
\boldsymbol{C}_{r r} & \widetilde{\boldsymbol{C}}_{r t} \\
\widetilde{\boldsymbol{C}}_{t r} & \boldsymbol{C}_{t t}+\widetilde{\boldsymbol{C}}_{t t}
\end{array}\right]\left[\begin{array}{c}
\dot{\boldsymbol{r}} \\
\dot{\boldsymbol{q}}_{t}
\end{array}\right]} \\
+\left[\begin{array}{ll}
\boldsymbol{K}_{r r} & \boldsymbol{\boldsymbol { K }}_{r t} \\
\widetilde{\boldsymbol{K}}_{t r} & \boldsymbol{K}_{t t}+\widetilde{\boldsymbol{K}}_{t t}
\end{array}\right]\left[\begin{array}{c}
\boldsymbol{r} \\
\boldsymbol{q}_{t}
\end{array}\right]=\left[\begin{array}{c}
\mathbf{0} \\
\widetilde{\boldsymbol{F}}_{Q}
\end{array}\right]
\end{gathered}
$$

The number of differential equations decreases by $N$ compared to the set of motion equations (7), which significantly reduces the time of calculations, even though the degree of the computational complexity of the algorithm increases due to the appearance of additional timedependent blocks in the inertia and damping matrix.

\section{Numerical analysis results}

In order to perform numerical analyzes, two alternative calculation algorithms based on equations (7) and (8) were developed in the MATLab programming environment. In both algorithms, the Newmark method was used to integrate the equations of motion with the parameter $\beta=1 / 4$ ensuring the unconditional stability of the method. The input data modeled on the work [9] was used for the calculations, while the longer track section was used for the analysis, i.e. the $100 \mathrm{~m}$ section. The elasticity and damping factors of the track base are, respectively: $k=1,1 \cdot 10^{8} \mathrm{~N} / \mathrm{m}^{2}, c=2,8667 \cdot 10^{5} \mathrm{Ns} / \mathrm{m}^{2}$, the bending stiffness of the beam modeling two railways is $E J=1,2831 \cdot 10^{7} \mathrm{Nm}^{2}$ and its unit mass $m=1,21 \cdot 10^{2} \mathrm{~kg} / \mathrm{m}$.

The calculations took into account material damping in rails with a retardation time of $2,1 \cdot 10^{-5} \mathrm{~s}$. Track vibrations are driven by a Shinkansen train, which consists of eight 25 -meter repetitive vehicles. Wheelbases, mass parameters, and suspension characteristics were adopted according to the data from monograph [11]. The rigidity of Hertz's susceptible contact stress was varied taking $k_{\mathrm{H}}=1,4 \cdot 10^{8} \mathrm{~N} / \mathrm{m}$ as the base value (based on [4] and [6]) and then $k_{\mathrm{H}}=1,4 \cdot 10^{7} \mathrm{~N} / \mathrm{m}$ and $k_{\mathrm{H}}=1,4 \cdot 10^{9} \mathrm{~N} / \mathrm{m}$. The track section was divided into 200 finite elements of equal length, a step of $0.0001 \mathrm{~s}$ was adopted for numerical integration.

The displacements, velocities, and accelerations of the body vibrations of the first of eight vehicles and the front carriage of the first vehicle, as well as the track at three points: in $1 / 4,3 / 4$ and $3 / 4$ the length of the tested section were analyzed. Simulations were performed using two previously discussed calculation algorithms at different train speeds: 30,60 and $90 \mathrm{~m} / \mathrm{s}(108$, 216 and $324 \mathrm{~km} / \mathrm{h}$ ), assessing the impact of contact stress susceptibility on system vibration simulations. It was found that this impact does not depend significantly on the adopted travel speed of the train, so the following figures show only examples of the speed of $30 \mathrm{~m} / \mathrm{s}$. Besides, it turned out that the adoption of a susceptible contact stress with a typical stiffness $k_{\mathrm{H}}=1,4 \cdot 10^{8} \mathrm{~N} / \mathrm{m}$, instead of a rigid spring, does not visibly affect the course of track displacements, and the conclusions regarding vibration speed and acceleration do not depend on the choice of track cross-section. For this reason, Figure $\mathbf{4}$ only shows the waveforms of velocity and acceleration of vibrations in the cross-section $x=0,25 \mathrm{~L}$.

The analysis of the charts presented in Figure 4 leads to the conclusion that the use of Hertzian flexible spring at the contact of the wheelsets with the track, instead of the rigid spring, causes slight differences between solutions, consisting in a slight reduction in peak values and smoothing waveform forms. This is more accurately illustrated in Figure 5, which shows a selected fragment of the acceleration waveforms. 

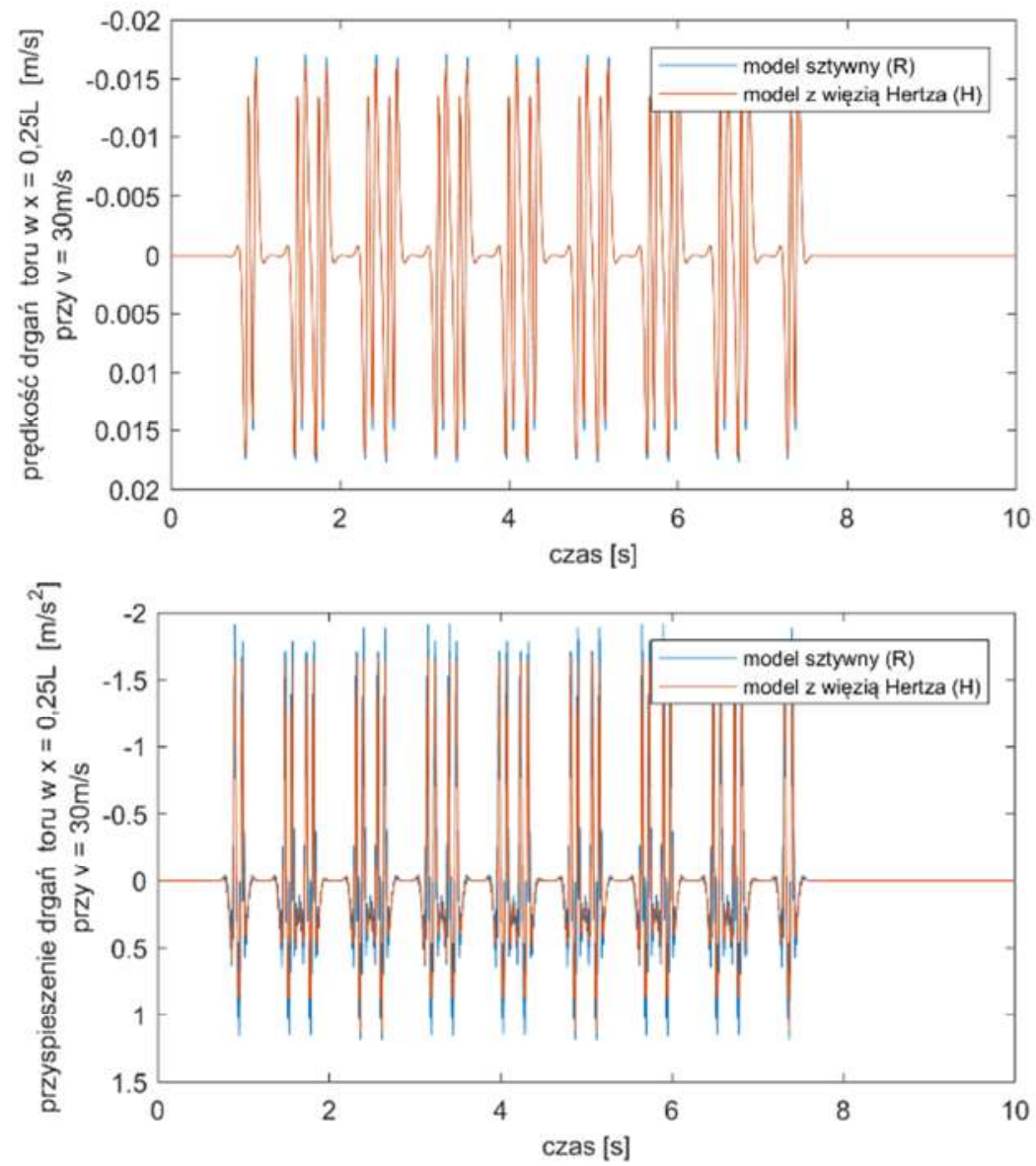

4. Velocity and acceleration of track vibration in cross section $x=0,25 \mathrm{~L}$

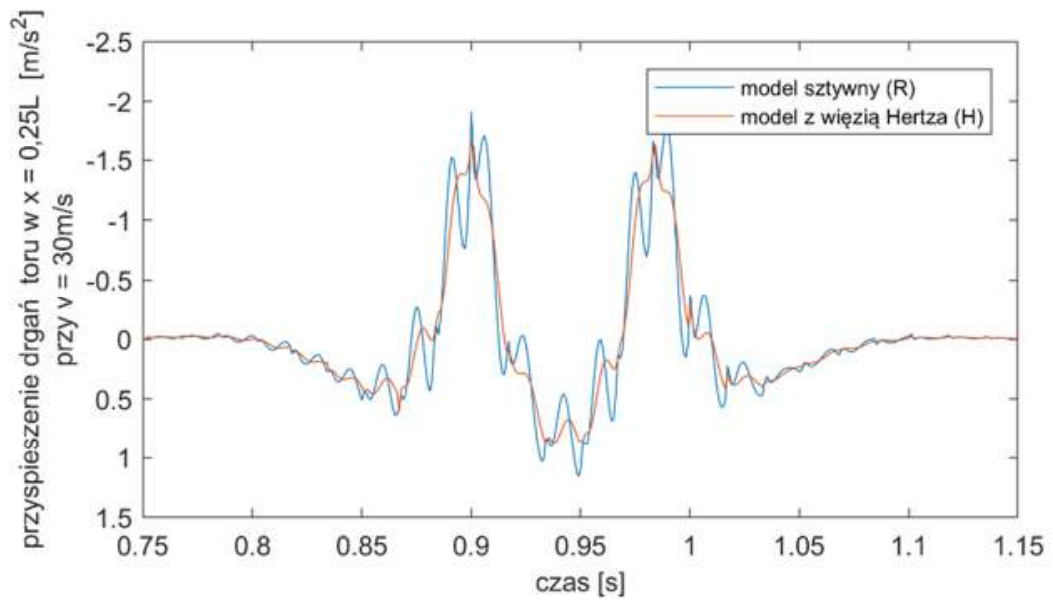

5. Fragment of courses of acceleration of track vibration in cross-section $x=0,25 \mathrm{~L}$ 


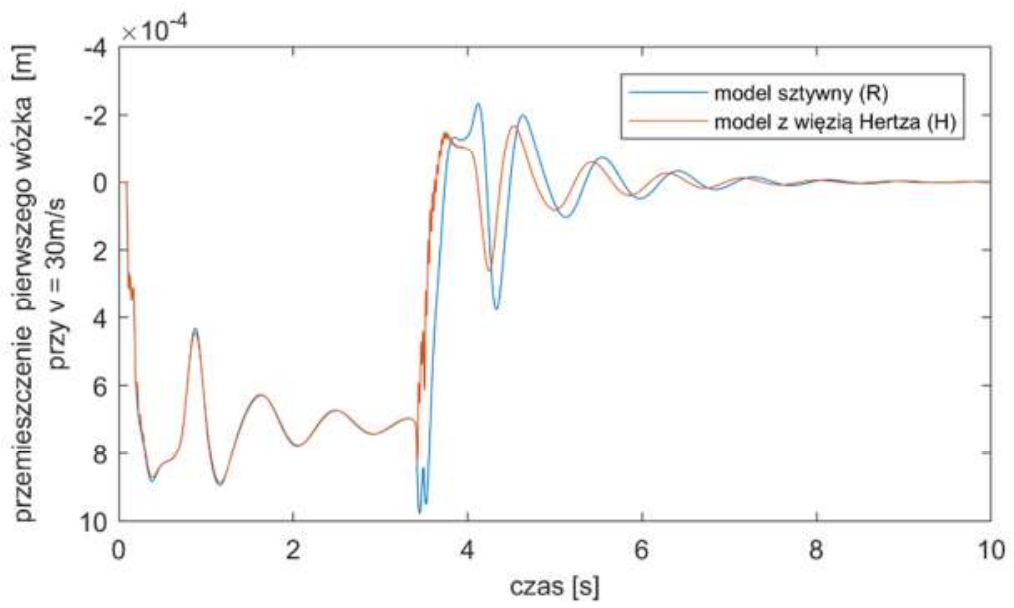

6. Vertical vibration of the front bogie on the first vehicle

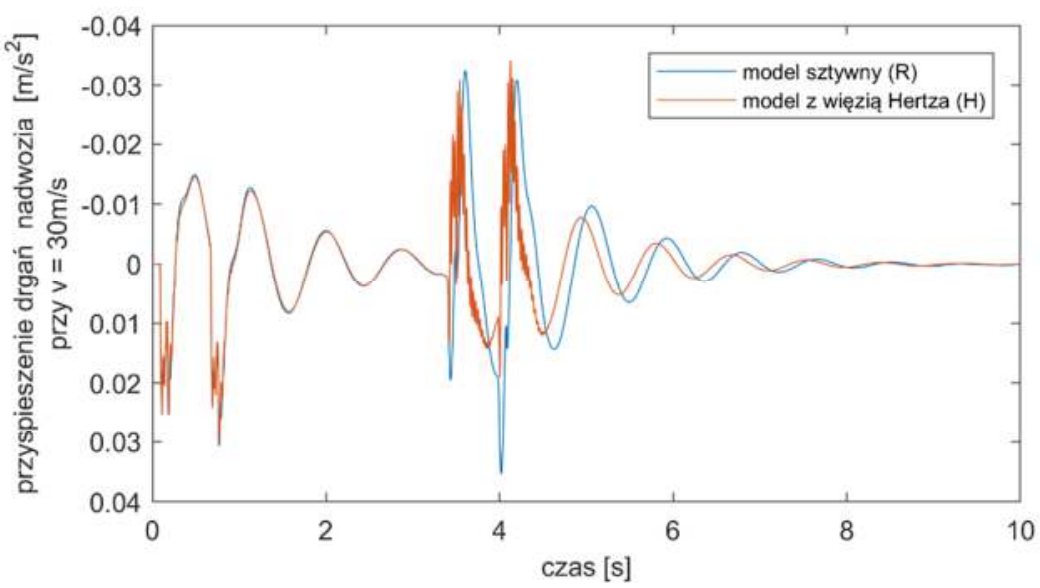

7. Acceleration of the first vehicle body

Figure 6 shows the vertical vibration waveforms of the front carriage of the first repeating unit of the train, and Figure 7 shows the acceleration of vertical vibration of the vehicle body. The prevailing influence on the shape of the graphs presented has a threshold effect at the beginning and end of the movement, resulting from entering the deformable section of the track and exit from this section. The crossing of a deformable section of track at a speed of 30 $\mathrm{m} / \mathrm{s}$ lasts $3.33 \mathrm{~s}$, and then the vehicle re-enters the completely undeformable track, where after a short transition period it performs fading free vibrations. During the transition period, the effect of the second axle of the bogie entering the non-deformable track as well as the effect of the second bogie of the same vehicle appears in the vibrations of the truck. In the case of acceleration of body vibrations, only the effect of entering the second bogie is visible. Solutions are similarly shaped in the initial phase of vehicle movement, but the threshold effect is smaller, among others because when entering a deformable section of the track, the dynamic displacements of the vehicle and their speeds are zero.

Unlike the initial phase of the movement, after leaving the vehicle from a deformable section of the track, we observe visible differences between solutions determined using a flexible and rigid contact stress. Both in the case of truck displacements and body accelerations, the introduction of deformable contact stresses into the calculation model results in a reduction in amplitudes and phase shift of the waveforms (Figures 6 and 7). 
Besides, additional high-frequency oscillations appear in the vibration waveforms that result from the local vibration of the wheelsets. Figure 8 shows examples of these vibration waveforms generated at three different Hertzian spring stiffness and a traveling speed of 60 $\mathrm{m} / \mathrm{s}$. The accompanying vertical vibration waveforms of the first bogie are shown in Figure 9 . It can be seen that the greater the rigidity of the contact spring, the smaller the free vibration period and the faster the local vibration of the wheelset disappears. The dynamic displacement of a wheelset is determined, as is the track displacement of the track (see [9]). Also, as stated based on Figure 9, the stiffness of the contact spring cannot be chosen too low, as it may lead to degeneration (overestimation) of the vehicle and thus the track vibrations. Adopting the value of $k_{\mathrm{H}}=1,4 \cdot 10^{8} \mathrm{~N} / \mathrm{m}$ recommended in the literature [4] seems to be a reasonable compromise because it gives results not significantly different from those obtained with the use of a rigid spring (Figures 4-7) and at the same time leaves the wheelset free to move vertically.

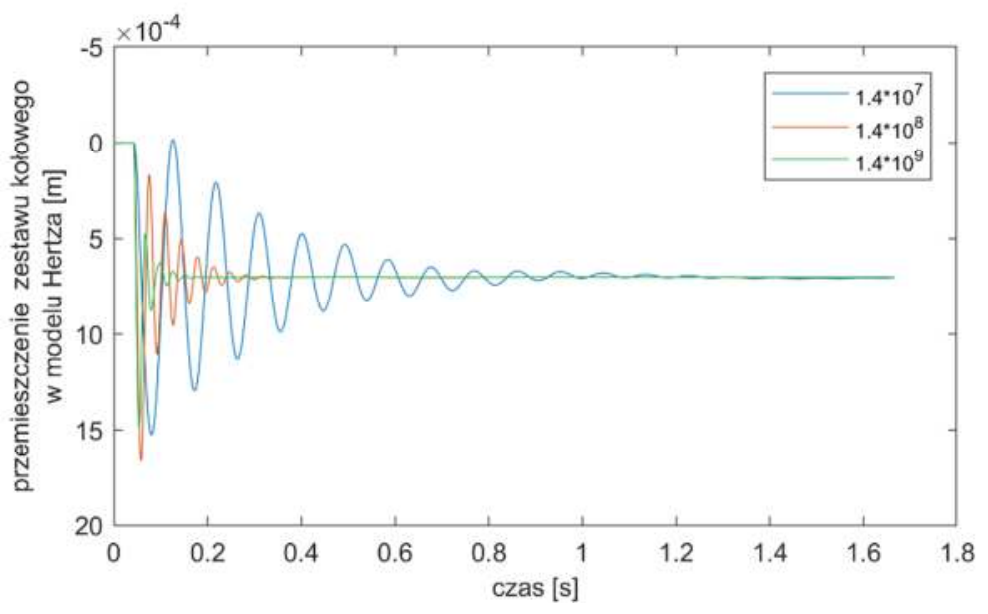

8. The vibrations of the front wheelset on the first vehicle, depending on the rigidity of Hertzian contact spring

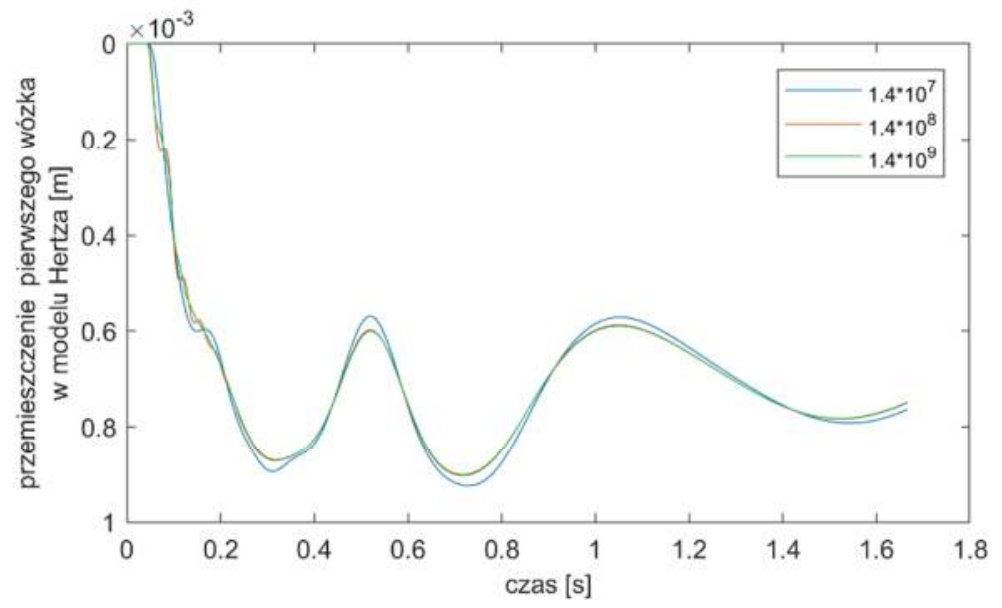

9. Vertical vibration of the front bogie on the first vehicle, depending on the rigidity of Hertzian contact stress 


\section{Conclusions}

The paper presents and compares two methods of train-track system vibration simulation, differing in the wheel-rail contact model used. In the first method, a model in the form of a two-way, susceptible Hertzian type contact stress was used, in the second method - a model in the form of a non-deformable spring. In both methods, a flat system calculation model was adopted, consisting of a Euler-Bernoulli beam resting on a Winkler-type elastic-damping substrate and a set of rail vehicles with two-stage suspension, modeled by dynamic systems with ten degrees of laxity. The results of numerical analyzes were presented, whose purpose was to determine the impact of taking into account the susceptibility of bilateral contact stresses on the results of vibration simulation of the considered system. It was found that the replacement of rigid contact stresses by two-way Hertzian type susceptible stresses with typical stiffness recommended in the literature has no effect on track vibration simulations and the impact on acceleration simulations is insignificant, regardless of the traveling speed. The visible effect is a slight reduction in the oscillation peaks of displacements and accelerations of vehicle structural elements. It follows that vehicle solutions, determined with rigid contact ties, are conservative solutions, i.e. beneficial from a safety point of view in the design of structures. The use of two-way Hertzian springs in the computational model of the train-track system often practiced in modern literature, therefore there is no significant justification.

The introduction of constraints susceptible to wheel-rail contact is justified when these constraints are treated as one-way, i.e. not stretching. They allow you to take into account the temporary detachment of wheelsets from the track, which appear, among others at high traveling speeds causing the high acceleration of track and wheelsets vibrations ([9]). It should be assumed that the dynamic effects resulting from the temporary loss of wheel-rail contact can be significant. This problem will be the subject of further research of the authors, which will be conducted using the simulation method presented in this work, after minor modifications. The introduced modifications of the method will allow observation of the reaction of each susceptible contact stress in each calculation step and assume zero stiffness of this spring when it is stretched. This work should be treated as the first stage of research leading to the assessment of the impact of wheel rolling surface separation from rails on the dynamic response of the train-track system. It is worth noting that the numerical studies presented in this work have already shown that the simulation method works correctly in the zones of full contact of the wheels with the rails if the rigidity of the virtual contact stress is properly selected.

\section{Source materials}

[1] Kalker J. J., Review of wheel-rail rolling contact theories, the general problem of rolling contact, Applied Mechanics Division (ASME, New York), 40, 1980, 77-92.

[2] Garg V.K., Dukkipati R.V., Dynamics of railway vehicle systems, Academic Press, New York, 1984.

[3] Bosso N., Spiryagin M., Gugliotta A., Somá A., Mechatronic Modeling of Real-Time Wheel-Rail Contact, Springer-Verlag, Berlin Heidelberg, 2013.

[4] Esveld C., Modern Railway Track, MRT-Productions, The Netherlands, 2014.

[5] Romero A., Galvín P., Domínguez J., A time domain analysis of train induced vibrations, Earthquakes and Structures, 3(3), 2012, 297-313.

[6] Podwórna M., Klasztorny M., Wpływ cech pojazdów szynowych na odpowiedź dynamiczna mostu belkowego, Drogi i Mosty, 3, 2011, 63-87.

[7] Chojnacki W., Więź kontaktowa typu Hertza w symulacjach numerycznych drgań uktadu pociag - tor, Praca magisterska WBLiW PWr, 2018.

[8] Langer J., Dynamika budowli, Wyd. Polit. Wrocł., Wrocław, 1980. 
[9] Bryja, D., Gisterek, I., Popiołek, A., Analiza numeryczna wpływu nierówności progowej na drgania toru kolejowego spowodowane przejazdem pociagu dużch prędkości, Inżynieria i Budownictwo, 71(10), 2015, 532-536.

[10] Bryja D., Hołubowski R., Modelowanie belkowych mostów kolejowych $z$ zastosowaniem metody GFEM. Część I. Sformułowanie teoretyczne, Zeszyty Naukowe Polit. Rzeszowskiej nr 283, seria Budownictwo i Inżynieria Środowiska, z. 59, 2012, 5-19.

[11] Klasztorny M., Dynamika mostów belkowych obciążonych pociagami szybkobieżnymi, Wydawnictwa Naukowo-Techniczne, Warszawa, 2005. 